OPEN ACCESS

Edited by: Bernard Attali,

Tel Aviv University, Israel

Reviewed by: Carmen Melendez-Vasquez, Hunter College (CUNY), United States

Esperanza Bas Infante, University of Miami, United States

*Correspondence: Victor Shahin shahin@uni-muenster.de

Received: 21 June 2017 Accepted: 11 October 2017 Published: 25 October 2017

Citation:

Rosso G, Young P and Shahin V (2017) Implications of Schwann Cells Biomechanics and Mechanosensitivity for Peripheral Nervous System Physiology and Pathophysiology.

Front. Mol. Neurosci. 10:345. doi: 10.3389/fnmol.2017.00345

\section{Implications of Schwann Cells Biomechanics and Mechanosensitivity for Peripheral Nervous System Physiology and Pathophysiology}

\author{
Gonzalo Rosso ${ }^{1}$, Peter Young ${ }^{2}$ and Victor Shahin ${ }^{1 *}$ \\ ${ }^{1}$ Institute of Physiology II, University of Münster, Münster, Germany, ${ }^{2}$ Department of Sleep Medicine and Neuromuscular \\ Disorders, University of Münster, Münster, Germany
}

The presence of bones around the central nervous system (CNS) provides it with highly effective physiologically crucial mechanical protection. The peripheral nervous system (PNS), in contrast, lacks this barrier. Consequently, the long held belief is that the PNS is mechanically vulnerable. On the other hand, the PNS is exposed to a variety of physiological mechanical stresses during regular daily activities. This fact prompts us to question the dogma of PNS mechanical vulnerability. As a matter of fact, impaired mechanics of PNS nerves is associated with neuropathies with the liability to mechanical stresses paralleled by significant impairment of PNS physiological functions. Our recent biomechanical integrity investigations on nerve fibers from wild-type and neuropathic mice lend strong support in favor of natural mechanical protection of the PNS and demonstrate a key role of Schwann cells (SCs) therein. Moreover, recent works point out that SCs can sense mechanical properties of their microenvironment and the evidence is growing that SCs mechanosensitivity is important for PNS development and myelination. Hence, SCs exhibit mechanical strength necessary for PNS mechanoprotection as well as mechanosensitivity necessary for PNS development and myelination. This mini review reflects on the intriguing dual ability of SCs and implications for PNS physiology and pathophysiology.

\begin{abstract}
Keywords: peripheral nervous system (PNS) development and regeneration, PMP22-associated PNS neuropathies, Schwann cells, mechanosensitivity, mechanical interactions between cells and the extracellular matrix
\end{abstract}

\section{INTRODUCTION}

The general assumption that the peripheral nervous system (PNS) is prone to mechanical injuries is based on the absence of a formidable physical barrier in the PNS that presents the skull and bony vertebrae in the central nervous system (CNS). Lack of mechanical protection or mechanical strength, however, should impede the physiological activities of the PNS. Take for example the primary nerve function that is the propagation of action potentials. Conduction velocity is used as a criterion to classify nerves. While some nerves exhibit a conduction velocity as low as $0.1 \mathrm{~ms}^{-1}$ others exhibit a very high velocity up to $100 \mathrm{~ms}^{-1}$ which is of paramount importance for vital 
physiological responses (Debanne, 2004). The presence of a myelin sheath around nerve fibers is one of the critical factors ensuring a high conduction velocity. Another critical factor is the axon caliber; the larger the faster. Consequently, liability to mechanical compression would substantially slow down the conduction velocity or induce conduction block and the resulting pathophysiological consequences would be severe. Hence, the assumption that the PNS lacks mechanical strength is somewhat shaky and should be reconsidered. The question is pertinent as to whether major constituents of the PNS provide it with natural mechanical strength. Likely candidates are several tissues and extracellular matrices (ECMs) within PNS nerves (Colognato et al., 2005) which may offer some mechanical support. In the PNS, every individual nerve fiber is wrapped in a protective sheath known as the endoneurium. In addition, fibers are bundled in fascicles possessing a protective lining termed perineurium. Fascicles in turn are joined together with a blood supply and fatty tissue within yet another layer known as the epineurium. Unlike oligodendrocytes and their associated axons in the CNS, Schwann cells (SCs) and axons in the PNS are enveloped in a basal lamina, a specialized form of ECM (Colognato et al., 2005). The fairly thin basal lamina is mainly secreted by SCs (Obremski et al., 1993). Different roles have been proposed for the basal lamina including SC proliferation, survival, migration and myelination (Colognato et al., 2005; Court et al., 2006; Chernousov et al., 2008; Colognato and Tzvetanova, 2011; Pereira et al., 2012). The role of the basal lamina in providing mechanical strength to PNS nerves has recently been demonstrated (Rosso et al., 2014) and will be discussed in the present review. Besides, recent observations in vitro demonstrate that SCs are capable of sensing the mechanical stiffness of their ECM proteincoated substrate (Rosso et al., 2017). Mechanosensitivity strongly impacts SCs shape, migration, adhesion and mechanics (Rosso et al., 2017) and is thus assumed to play key roles in PNS development, maintenance, myelination and regeneration as discussed here.

\section{MECHANOSENSITIVITY}

It should be noted that cells interactions with ECMs is inherently not only biochemical but also strongly mechanical (Discher et al., 2005). There is overwhelming evidence for the importance of mechanical interactions between the ECM and cells as shown for diverse cell types (Even-Ram et al., 2006; Discher et al., 2009; Franze, 2013). Tissue cells are naturally not suspended in fluid but anchored which is essential for their viability. Anchorage on the other hand exposes cells to mechanical forces imposed upon them by the physical properties of their environment, in particular the ECM stiffness (Discher et al., 2005). Nearly two decades ago, a study was published which revealed how differently fibroblasts looked and moved on substrates with the same chemical properties but different stiffness (Pelham and Wang, 1997). Intriguingly, fibroblast locomotion and focal adhesion were regulated by the stiffness of their substrate. Simulated by these findings, diverse follow-up studies were published (Engler et al., 2004, 2006; Gilbert et al., 2010; Arulmoli et al., 2015; Sosale et al., 2015). In some instances mechanical properties of the microenvironment were observed to modify or even override chemical signals (Engler et al., 2006). Hence, it is meantime beyond doubt that the feedback of local ECM stiffness on the cell state has profound implications for development, differentiation, disease, and regeneration (Discher et al., 2005). However, the exact mechanism underlying stiffness sensing remains unclear (Tee et al., 2009; Moore et al., 2010; Franze et al., 2013; Humphrey et al., 2014). Mechanosensing of the environment is within microseconds followed by transmission of the gathered information to the cell nucleus to trigger a biochemical response in a physiological process known as mechanotransduction (Jaalouk and Lammerding, 2009; Wang et al., 2009). Cytoskeletal proteins, integrins, nesprins and the nuclear lamina are among the diverse proteins involved in the transmission process (Jaalouk and Lammerding, 2009; Wang et al., 2009). Mutation or misregulation of any proteins involved in mechanotransduction is closely associated with the onset and progression of diverse diseases ranging from muscular dystrophies to cardiomyopathies, cancer and neuropathies among others (Franze, 2013; Franze et al., 2013). Numerous studies highlight the importance of mechanotransduction for the nervous system thereby prompting a new branch of neurosciences termed neuromechanics (Franze, 2011). Diverse types of neurons and glial cells of the CNS have been shown to respond strongly to the stiffness of their substrate (Flanagan et al., 2002; Georges et al., 2006; Jiang et al., 2008; Rosenberg et al., 2008; Moshayedi et al., 2010). Substrate stiffness has profound influence on the morphology, development, networking, dynamics, behavior and function of neuronal and glial cells (Kostic et al., 2007; Previtera et al., 2010; Cellot et al., 2011; Fabbro et al., 2012; Tang et al., 2013; Zhang et al., 2014). Neuronal cells may even use stiffness gradients of their surrounding as a guidance for their migration, a process referred to as mechanotaxis (Franze, 2011). Unlike the CNS which certainly received some attention so far, the importance of mechanosensitivity for the PNS is just beginning to be recognized (Koch et al., 2012; Athamneh et al., 2015; Poitelon et al., 2016; Urbanski et al., 2016; Rosso et al., 2017).

\section{SCHWANN CELLS}

The principal glial cells of PNS are SCs. The generation of SCs is a multi-step process termed SC lineage (Mirsky and Jessen, 1996; Jessen and Mirsky, 2005). It starts from the migrating neural crest cells from the dorsal root ganglion, which develop first to SC precursors and then to immature SCs (Jessen and Mirsky, 2005). Immature SCs undergo a transition to two different cell types, myelinating and non-myelinating SCs. This decision of immature SCs on their fate as myelinating or non-myelinating is still puzzling (Jessen and Mirsky, 2005). All immature SC are held to share the same developmental potential and their decision to become myelinating or non-myelinating is determined by the axon they associate with Jessen and Mirsky (2005). It is well-known that only axons larger than $\sim 1 \mu \mathrm{m}$ 
in diameter are myelinated (Jessen and Mirsky, 2005) and that axonal Neuregulin-1 (NRG1) signaling is a prerequisite (Michailov et al., 2004; ffrench-Constant et al., 2004; Taveggia et al., 2005; Pereira et al., 2012; Heller et al., 2014). Nevertheless, the triggers for myelination and the resulting downstream signaling are still a matter of intense debate (Pereira et al., 2012). The two types of SCs play different roles in the PNS and both are pivotal for its maintenance (Jessen and Mirsky, 1999). The production and wrapping of myelin around axons permits fast conduction of signaling essential for the nervous system function. In addition to myelin production, SCs carry out numerous tasks that are indispensable for the development, physiological support, survival, protection and regeneration of the PNS (Jessen and Mirsky, 1999). Several of these functions in turn, are mediated by the basal lamina (Chernousov et al., 2008), whose production is a sequential process starting at the stage of immature SCs (Jessen and Mirsky, 2005).

\section{IMPLICATIONS OF SCHWANN CELLS MECHANOSENSITIVITY FOR PNS DEVELOPMENT, MYELINATION AND REGENERATION}

Exposure of SCs to mechanical force begins right from the early embryonic stages and is maintained throughout life. Among the major forces is the substantial increase in the stiffness of
SCs microenvironment along their morphogenesis (Figure 1). This is due to progressive production of connective tissue and basal lamina which peaks in the stage of mature SCs (Jessen and Mirsky, 2005; Figure 1). Eventually, mature SCs are sandwiched between the ECM, the myelin and the axon, and surrounded by several connective tissues. Hence, maturation of SCs is paralleled by a dynamic change of the stiffness of their microenvironment. A recent work demonstrates with atomic force microscopy (AFM) measurements a consistent increase in the stiffness of peripheral nerves during development (Urbanski et al., 2016). Several lines of recent evidence demonstrate that SCs feel and respond to the stiffness of their substrate, and that mechanosensitivity plays key roles in SCs shape, adhesion, migration, differentiation, gene expression profiles and myelination (Gu et al., 2012; López-Fagundo et al., 2014; Fernando et al., 2016; Poitelon et al., 2016; Urbanski et al., 2016; Rosso et al., 2017). This strong impact of mechanosensitivity on SCs is of great importance for the PNS from biomedical and clinical aspects. Starting with PNS development, migration of SC precursors from embryonic DRGs is a fundamental step in PNS development. Adhesion is necessary for close interactions with outgrowing neurites in particular during the process of radial sorting for myelination of axons (Jessen and Mirsky, 2005; Brinkmann et al., 2008; Nave and Werner, 2014; Feltri et al., 2016). Differentiation and alteration of gene expression profiles are further critical steps during PNS development (Mirsky and Jessen, 1996; Jessen and Mirsky, 1999, 2005; Previtali et al., 2003; Pankov et al., 2005; Nodari et al., 2007; Leitman et al., 2011;

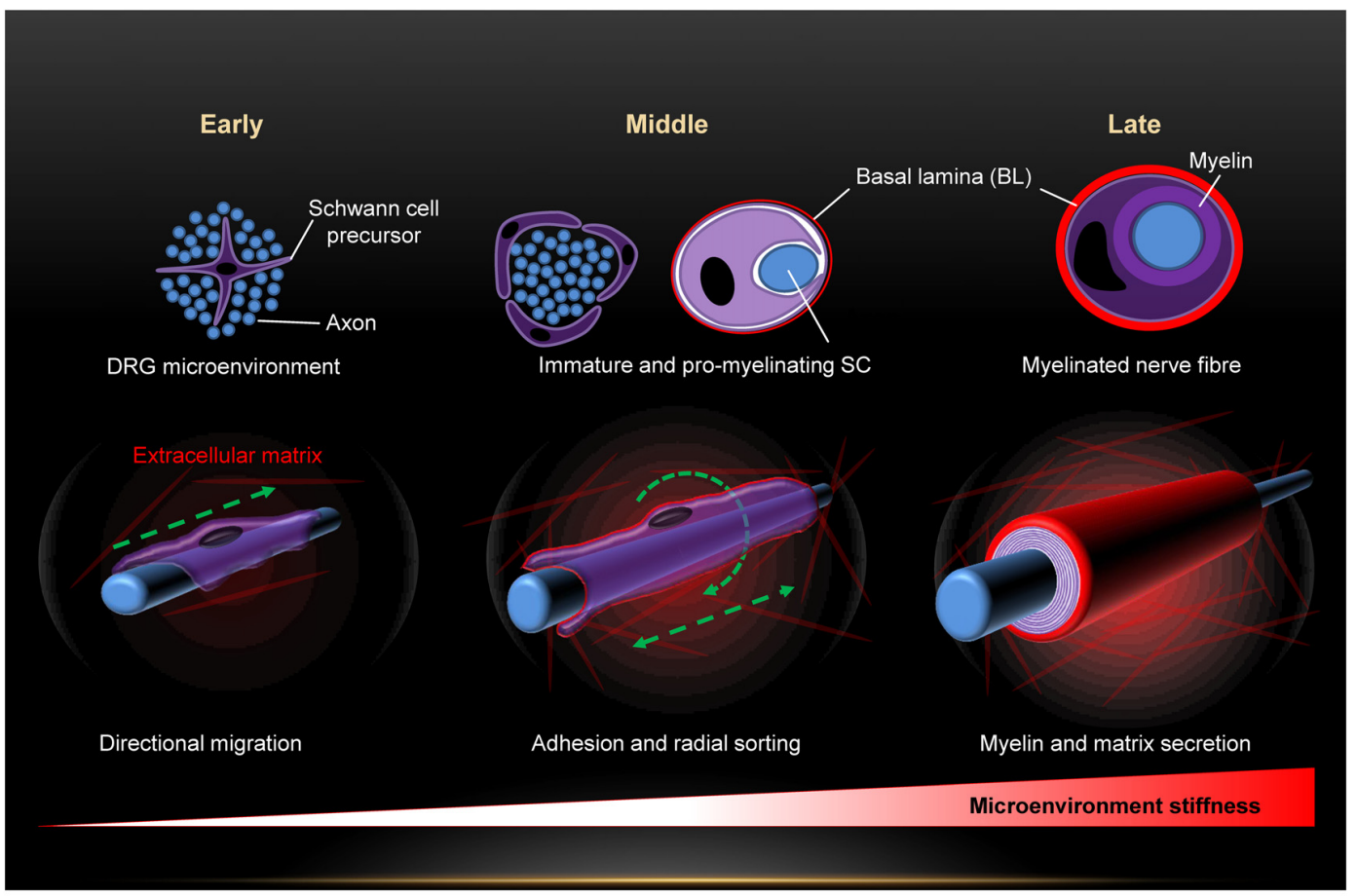

FIGURE 1 | Dynamic change of the mechanical microenvironment of Schwann cells (SCs) during the developmental stages (early, middle and late) of the peripheral nervous system (PNS). Sequential build-up of basal lamina and several tissues progressively increases the microenvironment stiffness. 
Poitelon et al., 2016; Quintes et al., 2016). The morphology of SCs is of substantial physiological relevance for it strongly affects their protein expression levels and biochemical signaling (Migliore and Shepherd, 2005; Pankov et al., 2005; Nodari et al., 2007; Mitchel and Hoffman-Kim, 2011). For instance, SCs switch their morphology from elongated lamellae to the extension of radial lamellae in order to switch from migration to axonal sorting and myelination (Nodari et al., 2007). This morphological transformation is triggered by a switch in $\beta 1$ integrin-activated Rac signaling (Nodari et al., 2007). Regeneration of the PNS upon injuries requires similar steps as in PNS development (Conforti et al., 2014). Transection of nerves following injury causes changes in the nerve stump distal to the injury that are collectively referred to as Wallerian degeneration (Jessen and Mirsky, 2008). Hallmarks are axon death, macrophages invasion, breakdown of myelin sheaths and transient phase of SCs proliferation, and the molecular expression pattern of SCs is reversed from that characteristic of mature myelinating and non-myelinating back to one characteristic of immature state (Jessen and Mirsky, 2008). Hence, SCs undergo dedifferentiation during certain PNS nerve injuries and will have to repeat major steps they take during PNS development. Investigation of PNS mechanosenstivity will not only substantially refine our insufficient understanding of PNS development but may also prove invaluable for clinical aid of nerve regeneration. The importance of including mechanosensitivity as a new key parameter in the design of nerve grafts is highlighted in recent works (Gu et al., 2011, 2012; Rosso et al., 2017). Under the influence of neurotrophic factors, the ECM and SCs, the proximal stump starts to sprout and elongate new axons in an attempt to regenerate the nerve. Elongation is mediated by the growth cones and the regeneration process occurs at a modest rate of $2-5 \mathrm{~mm} /$ day, which means that significant injuries may take very long (many months) to heal if at all ( $\mathrm{Gu}$ et al., 2011). Hence, the regeneration rate essentially runs a very tight race against the Wallerian degeneration (Gu et al., 2011). Medical intervention must therefore be swift and the increase of the regeneration rate is decisive for success. This is where efficient scaffolds come in to tip the scales in favor of nerve healing. Mechanosensitivity is gaining particular attention in nerve scaffolds bioengineering (Gu et al., 2011). It is also coming in the focus of myelination research. A wealth of information has been obtained about myelination mechanisms so far, but some questions remain open (ffrench-Constant et al., 2004; Michailov et al., 2004; Nave and Salzer, 2006; Brinkmann et al., 2008; Pereira et al., 2012; Poitelon et al., 2016; Urbanski et al., 2016). The evidence is compelling that neuronal growth factor NRG1 type III signals information about the size of the axons to SCs, and thus plays a key role in the determination of the myelination fate of axons (ffrench-Constant et al., 2004; Michailov et al., 2004; Pereira et al., 2012; Heller et al., 2014). NRG1 effect is mediated by interaction with the glial ErbB2 receptors (Brinkmann et al., 2008; Mei and Nave, 2014). Myosin II activity and vimentin are further factors involved in PNS myelination (Wang et al., 2008; Leitman et al., 2011; Triolo et al., 2012). Nevertheless, the triggers for myelination and the resulting downstream signaling are still debated (Pereira et al., 2012; Nave and Werner, 2014; Feltri et al., 2016). Recent works demonstrate that PNS myelination is highly sensitive to the mechanical stiffness of the substrate (Poitelon et al., 2016; Urbanski et al., 2016). Yap and Taz, effectors of the Hippo pathway, which are known to integrate chemical and mechanical signals in cells (Dupont et al., 2011), control mechanosensitive PNS myelination (Poitelon et al., 2016).

Yap and Taz are TEAD transcriptional activators. A recent study demonstrates that mechanosensitive activation of Yap and Taz in SCs is followed by their regulation of both SCs proliferation and transcription of basal lamina receptor genes, two actions necessary for radial sorting of axons and subsequent myelination (Poitelon et al., 2016). The same study also shows that Yap and Taz are required for the expression of integrin $\alpha_{6}$ and $\beta$-dystroglycan in SCs, and that laminin-binding integrins and dystroglycan are important downstream targets of Yap, Taz and TEAD transcription.

\section{IMPLICATIONS OF SCHWANN CELLS MECHANICS FOR PNS FUNCTION AND NEUROPATHIES}

Given the absence of a hard mechano-protective physical barrier around peripheral nerves, we put forward the following hypothesis: Inherent structural elements of peripheral nerves impart biomechanical resilience and integrity to nerves. To test this hypothesis, we designed experimental strategy based on simultaneous combination of atomic force with confocal microscopy (Rosso et al., 2014). Mechanical resilience and structural integrity of large and small caliber peripheral myelinated nerve fibers were investigated both upon exposure to three incremental loading forces as well as after removal of the forces. Tested adult myelinated peripheral nerve fibers withstand striking mechanical compression reversibly without apparent damage or loss of biomechanical and structural integrity. Loading forces gradually stepped up to $75 \mathrm{nN}$ compress the fibers. However, even the greatest force which causes substantial compression of fibers fails to disrupt their structural and functional integrity. This is striking taking into consideration the fact that the local loading force is exerted by a fairly sharp and rigid AFM tip which may be likened to a needle. The "needle", in turn, generates a very high local pressure with respect to the relationship between pressure, force and area. Far lower forces $(<2 \mathrm{nN})$ are generally needed to inflict substantial structural damage on cells when mechanically probed by a pyramidal AFM tip (Chiou et al., 2013). Hence, it is obvious that there is a natural mechanical protection of nerve fibers which makes up for the absence of a rigid physical barrier as in the CNS. It is also clear that mechanical resilience of peripheral nerve fibers must come from their intrinsic structural elements. Interestingly, neither the myelin sheaths nor the cytoskeleton significantly contribute to the biomechanical resilience of the nerve fibers but the fairly thin and flexible SCs basal lamina (Rosso et al., 2014). SCs basal lamina components typically include laminins, collagens and proteoglycans among other components (Court et al., 2006). Chemical digestion of collagens with collagenase leads 
to mechanical destabilization of myelinated nerve fibers (Rosso et al., 2014). Light mechanical compression of collagen-free fibers immediately results in a loss of their physiologically crucial tightness and in an irreversible structural deformation. The structural arrangement of the basal lamina plays a central role in mediation of the mechanoprotective effect (Rosso et al., 2014). A change of the basal lamina structural arrangement from a networked to a parallel orientation pattern, as observed in neuropathic Pmp22 $22^{-/-}$mice, is associated with a loss of the biomechanical integrity of nerve fibers; $P m p 22^{-/-}$mice are among the animal models to study the relationship between peripheral myelin protein 22 (PMP22) and the pathogenesis of hereditary PNS neuropathies (Adlkofer et al., 1995). The flexibility and particular structural arrangement of the thin basal lamina make it act much like a shock absorber or an armor, which reduces stress and tension on nerve fibers. Large mechanical forces exerted upon fibers are locally absorbed and dissipated thereby preventing fibers from mechanical vulnerability in a highly effective manner. PMP22 seems to contribute significantly to the mechanoprotective action of SCs basal lamina (Rosso et al., 2014). As a matter of fact, defects or mutations in PMP22 are a major cause of several hereditary peripheral neuropathies (Chance et al., 1993; Nicholson et al., 1994; Sereda et al., 1996; Suter and Scherer, 2003; Meyer Zu Hörste and Nave, 2006; Fledrich et al., 2014). PMP22 is crucial for the sealing, tightening and stabilization of myelin through its involvement in the assembly of myelin junctions, such as tight junctions and adherens (Guo et al., 2014). In addition, it is engaged in proliferation, differentiation and death of SCs (Jetten and Suter, 2000; Sancho et al., 2001; Amici et al., 2007), and the mechanical support of nerves (Bai et al., 2010). PMP22-associated PNS diseases such as Charcot-Marie-Tooth 1A (CMT1A; Fledrich et al., 2014) and hereditary neuropathy with liability to pressure palsies (HNPP) show mechanical vulnerability. Nerves from CMT1A rat model, with overexpression of PMP22 (Pmp22, gas-3), are prone to mechanical stresses (Sereda et al., 1996). Nerves from HNPP mouse model $\left(P m p 22^{+/-}\right)$fail to recover from a mechanically induced $60 \%-70 \%$ conduction block even after days (Bai et al., 2010), and they lose their physiologically crucial tightness to small and large molecules (Guo et al., 2014). Trembler-J mice $\left(\mathrm{Tr}-\mathrm{J} /{ }^{+}\right.$, mouse model for CMT1A) with a point mutation in $P m p 22$, exhibit impaired mechanical integrity. In $P m p 22^{-/-}$mice myelination is delayed and the basal lamina is loose (Amici et al., 2006), which indicates

\section{REFERENCES}

Adlkofer, K., Martini, R., Aguzzi, A., Zielasek, J., Toyka, K. V., and Suter, U. (1995). Hypermyelination and demyelinating peripheral neuropathy in Pmp22deficient mice. Nat. Genet. 11, 274-280. doi: 10.1038/ng1195-274

Amici, S. A., Dunn, W. A. Jr., Murphy, A. J., Adams, N. C., Gale, N. W., Valenzuela, D. M., et al. (2006). Peripheral myelin protein 22 is in complex with $\alpha 6 \beta 4$ integrin and its absence alters the Schwann cell basal lamina. J. Neurosci. 26, 1179-1189. doi: 10.1523/JNEUROSCI.2618-05. 2006

Amici, S. A., Dunn, W. A. Jr., and Notterpek, L. (2007). Developmental abnormalities in the nerves of peripheral myelin protein 22-deficient mice. J. Neurosci. Res. 85, 238-249. doi: 10.1002/jnr.21118 altered interactions of SCs with their basal lamina. Indeed, the levels of beta4 integrin, which is engaged in linking SCs with the basal lamina, are severely reduced in $P m p 22^{-/-}$mice (Amici et al., 2006). Together, the evidence is growing that PMP22 is not only important for the sealing of myelinated nerve fibers but also for their protection from mechanical stresses. PMP22 acts in concert with the basal lamina to provide PNS nerves with substantial biomechanical, structural and functional integrity. Myelin tightness and the ability of nerve fibers to withstand mechanical stresses and recover from compression are of paramount importance to ensure the physiologically critical high conduction velocity of myelinated nerves. Consequently, deficiencies, dysfunction or mutations in PMP22 and/or the basal lamina should have direct implications for PNS pathologies.

\section{CONCLUSION}

SCs provide crucial biomechanical support to the PNS at the single nerve fiber level by a concerted action of the basal lamina and PMP22. PNS neuropathies linked to SCs, basal lamina and PMP22 should be explored in depth from biomechanical aspects. Comprehensive investigation of SCs mechanosenstivity will substantially refine our understanding of PNS development, physiology and diseases. At the same time, it holds promise to significantly advance the worldwide urgent field of PNS injuries treatment strategies.

\section{AUTHOR CONTRIBUTIONS}

GR and VS designed the manuscript and the figure and wrote the final version. PY was involved in the medical and pathological aspects discussed throughout the manuscript. All three authors approved the final version of the manuscript.

\section{FUNDING}

This research was supported by funds from the Deutscher Akademischer Austauschdienst (DAAD) (PhD-Scholarship), Innovative Medizinische Forschung grants (IMF ILI211304, SH111208 and SH111511), and Deutsche Forschungsgemeinschaft (SH 167/6-1).

Arulmoli, J., Pathak, M. M., McDonnell, L. P., Nourse, J. L., Tombola, F., Earthman, J. C., et al. (2015). Static stretch affects neural stem cell differentiation in an extracellular matrix-dependent manner. Sci. Rep. 5:8499. doi: 10.1038/srep08499

Athamneh, A. I., Cartagena-Rivera, A. X., Raman, A., and Suter, D. M. (2015). Substrate deformation predicts neuronal growth cone advance. Biophys. J. 109, 1358-1371. doi: 10.1016/j.bpj.2015.08.013

Bai, Y., Zhang, X., Katona, I., Saporta, M. A., Shy, M. E., O’Malley, H. A., et al. (2010). Conduction block in PMP22 deficiency. J. Neurosci. 30, 600-608. doi: 10.1523/JNEUROSCI.4264-09.2010

Brinkmann, B. G., Agarwal, A., Sereda, M. W., Garratt, A. N., Müller, T., Wende, H., et al. (2008). Neuregulin-1/ErbB signaling serves distinct functions in myelination of the peripheral and central 
nervous system. Neuron 59, 581-595. doi: 10.1016/j.neuron.2008. 06.028

Cellot, G., Toma, F. M., Varley, Z. K., Laishram, J., Villari, A., Quintana, M., et al. (2011). Carbon nanotube scaffolds tune synaptic strength in cultured neural circuits: novel frontiers in nanomaterial-tissue interactions. J. Neurosci. 31, 12945-12953. doi: 10.1523/JNEUROSCI.1332-11.2011

Chance, P. F., Alderson, M. K., Leppig, K. A., Lensch, M. W., Matsunami, N., Smith, B., et al. (1993). DNA deletion associated with hereditary neuropathy with liability to pressure palsies. Cell 72, 143-151. doi: 10.1016/00928674(93)90058-X

Chernousov, M. A., Yu, W. M., Chen, Z. L., Carey, D. J., and Strickland, S. (2008). Regulation of Schwann cell function by the extracellular matrix. Glia 56, 1498-1507. doi: 10.1002/glia.20740

Chiou, Y. W., Lin, H. K., Tang, M. J., Lin, H. H., and Yeh, M. L. (2013). The influence of physical and physiological cues on atomic force microscopybased cell stiffness assessment. PLoS One 8:e77384. doi: 10.1371/journal.pone. 0077384

Colognato, H., ffrench-Constant, C., and Feltri, M. L. (2005). Human diseases reveal novel roles for neural laminins. Trends Neurosci. 28, 480-486. doi: 10.1016/j.tins.2005.07.004

Colognato, H., and Tzvetanova, I. D. (2011). Glia unglued: how signals from the extracellular matrix regulate the development of myelinating glia. Dev. Neurobiol. 71, 924-955. doi: 10.1002/dneu.20966

Conforti, L., Gilley, J., and Coleman, M. P. (2014). Wallerian degeneration: an emerging axon death pathway linking injury and disease. Nat. Rev. Neurosci. 15, 394-409. doi: 10.1038/nrn3680

Court, F. A., Wrabetz, L., and Feltri, M. L. (2006). Basal lamina: schwann cells wrap to the rhythm of space-time. Curr. Opin. Neurobiol. 16, 501-507. doi: 10.1016/j. conb.2006.08.005

Debanne, D. (2004). Information processing in the axon. Nat. Rev. Neurosci. 5, 304-316. doi: 10.1038/nrn1397

Discher, D. E., Janmey, P., and Wang, Y. L. (2005). Tissue cells feel and respond to the stiffness of their substrate. Science 310, 1139-1143. doi: 10.1126/science. 1116995

Discher, D. E., Mooney, D. J., and Zandstra, P. W. (2009). Growth factors, matrices, and forces combine and control stem cells. Science 324, 1673-1677. doi: 10.1126/science.1171643

Dupont, S., Morsut, L., Aragona, M., Enzo, E., Giulitti, S., Cordenonsi, M., et al. (2011). Role of YAP/TAZ in mechanotransduction. Nature 474, 179-183. doi: 10.1038/nature10137

Engler, A. J., Griffin, M. A., Sen, S., Bonnemann, C. G., Sweeney, H. L., and Discher, D. E. (2004). Myotubes differentiate optimally on substrates with tissue-like stiffness: pathological implications for soft or stiff microenvironments. J. Cell Biol. 166, 877-887. doi: 10.1083/jcb.200405004

Engler, A. J., Sen, S., Sweeney, H. L., and Discher, D. E. (2006). Matrix elasticity directs stem cell lineage specification. Cell 126, 677-689. doi: 10.1016/j.cell. 2006.06.044

Even-Ram, S., Artym, V., and Yamada, K. M. (2006). Matrix control of stem cell fate. Cell 126, 645-647. doi: 10.1016/j.cell.2006.08.008

Fabbro, A., Bosi, S., Ballerini, L., and Prato, M. (2012). Carbon nanotubes: artificial nanomaterials to engineer single neurons and neuronal networks. ACS Chem. Neurosci. 3, 611-618. doi: 10.1021/cn300048q

Feltri, M. L., Poitelon, Y., and Previtali, S. C. (2016). How schwann cells sort axons: new concepts. Neuroscientist 22, 252-265. doi: 10.1177/1073858415572361

Fernando, R. N., Cotter, L., Perrin-Tricaud, C., Berthelot, J., Bartolami, S., Pereira, J. A., et al. (2016). Optimal myelin elongation relies on YAP activation by axonal growth and inhibition by Crb3/Hippo pathway. Nat. Commun. 7:12186. doi: $10.1038 /$ ncomms 12186

ffrench-Constant, C., Colognato, H., and Franklin, R. J. (2004). Neuroscience. The mysteries of myelin unwrapped. Science 304, 688-689. doi: 10.1126/science. 1097851

Flanagan, L. A., Ju, Y. E., Marg, B., Osterfield, M., and Janmey, P. A. (2002). Neurite branching on deformable substrates. Neuroreport 13, 2411-2415. doi: 10.1097/00001756-200212200-00007

Fledrich, R., Stassart, R. M., Klink, A., Rasch, L. M., Prukop, T., Haag, L., et al. (2014). Soluble neuregulin-1 modulates disease pathogenesis in rodent models of Charcot-Marie-Tooth disease 1A. Nat. Med. 20, 1055-1061. doi: $10.1038 / \mathrm{nm} .3664$
Franze, K. (2011). Atomic force microscopy and its contribution to understanding the development of the nervous system. Curr. Opin. Genet. Dev. 21, 530-537. doi: 10.1016/j.gde.2011.07.001

Franze, K. (2013). The mechanical control of nervous system development. Development 140, 3069-3077. doi: 10.1242/dev.079145

Franze, K., Janmey, P. A., and Guck, J. (2013). Mechanics in neuronal development and repair. Annu. Rev. Biomed. Eng. 15, 227-251. doi: 10.1146/annurev-bioeng071811-150045

Georges, P. C., Miller, W. J., Meaney, D. F., Sawyer, E. S., and Janmey, P. A (2006). Matrices with compliance comparable to that of brain tissue select neuronal over glial growth in mixed cortical cultures. Biophys. J. 90, 3012-3018. doi: 10.1529/biophysj.105.073114

Gilbert, P. M., Havenstrite, K. L., Magnusson, K. E., Sacco, A., Leonardi, N. A., Kraft, P., et al. (2010). Substrate elasticity regulates skeletal muscle stem cell self-renewal in culture. Science 329, 1078-1081. doi: 10.1126/science. 1191035

Gu, X., Ding, F., Yang, Y., and Liu, J. (2011). Construction of tissue engineered nerve grafts and their application in peripheral nerve regeneration. Prog. Neurobiol. 93, 204-230. doi: 10.1016/j.pneurobio.2010.11.002

Gu, Y., Ji, Y., Zhao, Y., Liu, Y., Ding, F., Gu, X., et al. (2012). The influence of substrate stiffness on the behavior and functions of Schwann cells in culture. Biomaterials 33, 6672-6681. doi: 10.1016/j.biomaterials.2012.06.006

Guo, J., Wang, L., Zhang, Y., Wu, J., Arpag, S., Hu, B., et al. (2014). Abnormal junctions and permeability of myelin in PMP22-deficient nerves. Ann. Neurol. 75, 255-265. doi: 10.1002/ana.24086

Heller, B. A., Ghidinelli, M., Voelkl, J., Einheber, S., Smith, R., Grund, E., et al (2014). Functionally distinct PI 3-kinase pathways regulate myelination in the peripheral nervous system. J. Cell Biol. 204, 1219-1236. doi: 10.1083/jcb. 201307057

Humphrey, J. D., Dufresne, E. R., and Schwartz, M. A. (2014) Mechanotransduction and extracellular matrix homeostasis. Nat. Rev. Mol. Cell Biol. 15, 802-812. doi: 10.1038/nrm3896

Jaalouk, D. E., and Lammerding, J. (2009). Mechanotransduction gone awry. Nat. Rev. Mol. Cell Biol. 10, 63-73. doi: 10.1038/nrm2597

Jessen, K. R., and Mirsky, R. (1999). Schwann cells and their precursors emerge as major regulators of nerve development. Trends Neurosci. 22, 402-410. doi: 10.1016/s0166-2236(98)01391-5

Jessen, K. R., and Mirsky, R. (2005). The origin and development of glial cells in peripheral nerves. Nat. Rev. Neurosci. 6, 671-682. doi: 10.1038/nrn1746

Jessen, K. R., and Mirsky, R. (2008). Negative regulation of myelination: relevance for development, injury and demyelinating disease. Glia 56, 1552-1565. doi: 10.1002/glia.20761

Jetten, A. M., and Suter, U. (2000). The peripheral myelin protein 22 and epithelial membrane protein family. Prog. Nucleic Acid Res. Mol. Biol. 64, 97-129. doi: 10.1016/s0079-6603(00)64003-5

Jiang, F. X., Yurke, B., Firestein, B. L., and Langrana, N. A. (2008). Neurite outgrowth on a DNA crosslinked hydrogel with tunable stiffnesses. Ann. Biomed. Eng. 36, 1565-1579. doi: 10.1007/s10439-008-9530-Z

Koch, D., Rosoff, W. J., Jiang, J., Geller, H. M., and Urbach, J. S. (2012). Strength in the periphery: growth cone biomechanics and substrate rigidity response in peripheral and central nervous system neurons. Biophys. J. 102, 452-460. doi: 10.1016/j.bpj.2011.12.025

Kostic, A., Sap, J., and Sheetz, M. P. (2007). RPTP $\alpha$ is required for rigiditydependent inhibition of extension and differentiation of hippocampal neurons. J. Cell Sci. 120, 3895-3904. doi: 10.1242/jcs.009852

Leitman, E. M., Tewari, A., Horn, M., Urbanski, M., Damanakis, E., Einheber, S., et al. (2011). MLCK regulates Schwann cell cytoskeletal organization, differentiation and myelination. J. Cell Sci. 124, 3784-3796. doi: 10.1242/jcs. 080200

López-Fagundo, C., Bar-Kochba, E., Livi, L. L., Hoffman-Kim, D., and Franck, C. (2014). Three-dimensional traction forces of Schwann cells on compliant substrates. J. R. Soc. Interface 11:20140247. doi: 10.1098/rsif.2014.0247

Mei, L., and Nave, K. A. (2014). Neuregulin-ERBB signaling in the nervous system and neuropsychiatric diseases. Neuron 83, 27-49. doi: 10.1016/j.neuron.2014 06.007

Meyer Zu Hörste, G., and Nave, K. A. (2006). Animal models of inherited neuropathies. Curr. Opin. Neurol. 19, 464-473. doi: 10.1097/01.wco. 0000245369.44199 .27 
Michailov, G. V., Sereda, M. W., Brinkmann, B. G., Fischer, T. M., Haug, B., Birchmeier, C., et al. (2004). Axonal neuregulin-1 regulates myelin sheath thickness. Science 304, 700-703. doi: 10.1126/science.1095862

Migliore, M., and Shepherd, G. M. (2005). Opinion: an integrated approach to classifying neuronal phenotypes. Nat. Rev. Neurosci. 6, 810-818. doi: $10.1038 /$ nrn 1769

Mirsky, R., and Jessen, K. R. (1996). Schwann cell development, differentiation and myelination. Curr. Opin. Neurobiol. 6, 89-96. doi: 10.1016/s09594388(96)80013-4

Mitchel, J. A., and Hoffman-Kim, D. (2011). Cellular scale anisotropic topography guides Schwann cell motility. PLoS One 6:e24316. doi: 10.1371/journal.pone. 0024316

Moore, S. W., Roca-Cusachs, P., and Sheetz, M. P. (2010). Stretchy proteins on stretchy substrates: the important elements of integrin-mediated rigidity sensing. Dev. Cell 19, 194-206. doi: 10.1016/j.devcel.2010.07.018

Moshayedi, P., Costa, L. F., Christ, A., Lacour, S. P., Fawcett, J., Guck, J., et al. (2010). Mechanosensitivity of astrocytes on optimized polyacrylamide gels analyzed by quantitative morphometry. J. Phys. Condens. Matter 22:194114. doi: 10.1088/0953-8984/22/19/194114

Nave, K. A., and Salzer, J. L. (2006). Axonal regulation of myelination by neuregulin 1. Curr. Opin. Neurobiol. 16, 492-500. doi: 10.1016/j.conb.2006. 08.008

Nave, K. A., and Werner, H. B. (2014). Myelination of the nervous system: mechanisms and functions. Annu. Rev. Cell Dev. Biol. 30, 503-533. doi: 10.1146/annurev-cellbio-100913-013101

Nicholson, G. A., Valentijn, L. J., Cherryson, A. K., Kennerson, M. L., Bragg, T. L., DeKroon, R. M., et al. (1994). A frame shift mutation in the PMP22 gene in hereditary neuropathy with liability to pressure palsies. Nat. Genet. 6, 263-266. doi: 10.1038/ng0394-263

Nodari, A., Zambroni, D., Quattrini, A., Court, F. A., D’Urso, A., Recchia, A., et al. (2007). $\beta 1$ integrin activates Racl in Schwann cells to generate radial lamellae during axonal sorting and myelination. J. Cell Biol. 177, 1063-1075. doi: $10.1083 /$ jcb.200610014

Obremski, V. J., Wood, P. M., and Bunge, M. B. (1993). Fibroblasts promote Schwann cell basal lamina deposition and elongation in the absence of neurons in culture. Dev. Biol. 160, 119-134. doi: 10.1006/dbio.1993.1291

Pankov, R., Endo, Y., Even-Ram, S., Araki, M., Clark, K., Cukierman, E., et al. (2005). A Rac switch regulates random versus directionally persistent cell migration. J. Cell Biol. 170, 793-802. doi: 10.1083/jcb.200503152

Pelham, R. J. Jr., and Wang, Y. (1997). Cell locomotion and focal adhesions are regulated by substrate flexibility. Proc. Natl. Acad. Sci. U S A 94, 13661-13665. doi: $10.1073 /$ pnas.94.25.13661

Pereira, J. A., Lebrun-Julien, F., and Suter, U. (2012). Molecular mechanisms regulating myelination in the peripheral nervous system. Trends Neurosci. 35, 123-134. doi: 10.1016/j.tins.2011.11.006

Poitelon, Y., Lopez-Anido, C., Catignas, K., Berti, C., Palmisano, M., Williamson, C., et al. (2016). YAP and TAZ control peripheral myelination and the expression of laminin receptors in Schwann cells. Nat. Neurosci. 19, 879-887. doi: 10.1038/nn.4316

Previtali, S. C., Nodari, A., Taveggia, C., Pardini, C., Dina, G., Villa, A., et al. (2003). Expression of laminin receptors in schwann cell differentiation: evidence for distinct roles. J. Neurosci. 23, 5520-5530.

Previtera, M. L., Langhammer, C. G., Langrana, N. A., and Firestein, B. L. (2010). Regulation of dendrite arborization by substrate stiffness is mediated by glutamate receptors. Ann. Biomed. Eng. 38, 3733-3743. doi: 10.1007/s10439010-0112-5

Quintes, S., Brinkmann, B. G., Ebert, M., Frob, F., Kungl, T., Arlt, F. A., et al. (2016). Zeb2 is essential for Schwann cell differentiation, myelination and nerve repair. Nat. Neurosci. 19, 1050-1059. doi: 10.1038/nn.4321
Rosenberg, S. S., Kelland, E. E., Tokar, E., De la Torre, A. R., and Chan, J. R. (2008). The geometric and spatial constraints of the microenvironment induce oligodendrocyte differentiation. Proc. Natl. Acad. Sci. U S A 105, 14662-14667. doi: 10.1073/pnas.0805640105

Rosso, G., Liashkovich, I., Gess, B., Young, P., Kun, A., and Shahin, V. (2014). Unravelling crucial biomechanical resilience of myelinated peripheral nerve fibres provided by the Schwann cell basal lamina and PMP22. Sci. Rep. 4:7286. doi: 10.1038/srep07286

Rosso, G., Liashkovich, I., Young, P., Rohr, D., and Shahin, V. (2017). Schwann cells and neurite outgrowth from embryonic dorsal root ganglions are highly mechanosensitive. Nanomedicine 13, 493-501. doi: 10.1016/j.nano.2016. 06.011

Sancho, S., Young, P., and Suter, U. (2001). Regulation of Schwann cell proliferation and apoptosis in PMP22-deficient mice and mouse models of Charcot-Marie-Tooth disease type 1A. Brain 124, 2177-2187. doi: $10.1093 /$ brain/124.11.2177

Sereda, M., Griffiths, I., Puhlhofer, A., Stewart, H., Rossner, M. J., Zimmerman, F., et al. (1996). A transgenic rat model of Charcot-Marie-Tooth disease. Neuron 16, 1049-1060. doi: 10.1016/S0896-6273(00)80128-2

Sosale, N. G., Rouhiparkouhi, T., Bradshaw, A. M., Dimova, R., Lipowsky, R., and Discher, D. E. (2015). Cell rigidity and shape override CD47's "self"signaling in phagocytosis by hyperactivating myosin-II. Blood 125, 542-552. doi: 10.1182/blood-2014-06-585299

Suter, U., and Scherer, S. S. (2003). Disease mechanisms in inherited neuropathies. Nat. Rev. Neurosci. 4, 714-726. doi: 10.1038/nrn1196

Tang, M., Song, Q., Li, N., Jiang, Z., Huang, R., and Cheng, G. (2013). Enhancement of electrical signaling in neural networks on graphene films. Biomaterials 34, 6402-6411. doi: 10.1016/j.biomaterials.2013.05.024

Taveggia, C., Zanazzi, G., Petrylak, A., Yano, H., Rosenbluth, J., Einheber, S., et al. (2005). Neuregulin-1 type III determines the ensheathment fate of axons. Neuron 47, 681-694. doi: 10.1016/j.neuron.2005.08.017

Tee, S. Y., Bausch, A. R., and Janmey, P. A. (2009). The mechanical cell. Curr. Biol. 19, R745-R748. doi: 10.1016/j.cub.2009.06.034

Triolo, D., Dina, G., Taveggia, C., Vaccari, I., Porrello, E., Rivellini, C., et al. (2012). Vimentin regulates peripheral nerve myelination. Development 139, 1359-1367. doi: 10.1242/dev.072371

Urbanski, M. M., Kingsbury, L., Moussouros, D., Kassim, I., Mehjabeen, S., Paknejad, N., et al. (2016). Myelinating glia differentiation is regulated by extracellular matrix elasticity. Sci. Rep. 6:33751. doi: 10.1038/srep33751

Wang, H., Tewari, A., Einheber, S., Salzer, J. L., and Melendez-Vasquez, C. V. (2008). Myosin II has distinct functions in PNS and CNS myelin sheath formation. J. Cell Biol. 182, 1171-1184. doi: 10.1083/jcb.200802091

Wang, N., Tytell, J. D., and Ingber, D. E. (2009). Mechanotransduction at a distance: mechanically coupling the extracellular matrix with the nucleus. Nat Rev. Mol. Cell Biol. 10, 75-82. doi: 10.1038/nrm2594

Zhang, Q. Y., Zhang, Y. Y., Xie, J., Li, C. X., Chen, W. Y., Liu, B. L., et al. (2014). Stiff substrates enhance cultured neuronal network activity. Sci. Rep. 4:6215. doi: $10.1038 /$ srep06215

Conflict of Interest Statement: The authors declare that the research was conducted in the absence of any commercial or financial relationships that could be construed as a potential conflict of interest.

Copyright (c) 2017 Rosso, Young and Shahin. This is an open-access article distributed under the terms of the Creative Commons Attribution License (CC BY). The use, distribution or reproduction in other forums is permitted, provided the original author(s) or licensor are credited and that the original publication in this journal is cited, in accordance with accepted academic practice. No use, distribution or reproduction is permitted which does not comply with these terms. 